\title{
Atividades de investigação na disciplina de Ciências e desenvolvimento de habilidades cognitivas relacionadas a funções executivas
}

\author{
Investigative activities in disciplines of Science \\ and the development of cognitive skills of students \\ of basic education: relations with executive functions
}

\author{
Andréia de Freitas Zompero ${ }^{1}$. Carlos Eduardo de Souza Gonçalves ${ }^{2}$. \\ Carlos Eduardo Laburú ${ }^{3}$
}

\begin{abstract}
Resumo: O presente estudo discute o desenvolvimento de Habilidades Cognitivas dos estudantes ao realizarem as atividades de inquiry, relacionando-as a aspectos que envolvem a neurociência. Objetiva-se discutir e analisar como as atividades investigativas favorecem o desenvolvimento de Habilidades Cognitivas para investigação científica e ativam Funções Executivas, à luz dos estudos da Neuropsicologia, visto que as atividades investigativas cumprem o papel de estimular o raciocínio dos estudantes. Para atender aos objetivos propostos nesta pesquisa, procedeu-se a um estudo e posterior reflexão do referencial teórico sobre os fundamentos do inquiry, Habilidades Cognitivas para educação científica e Funções Executivas. Após, foi possível estabelecer convergências entre as Habilidades Cognitivas elencadas neste estudo com Funções Executivas. Como resultado, consideramos que a aplicação metodológica de atividades investigativas no ensino de Ciências aprimora Habilidades Cognitivas para investigação científica, bem como as Funções Executivas de Planejamento, Ação Propositiva e Monitoramento.
\end{abstract}

Palavras-chave: Ensino de ciências. Atividades investigativas. Funções executivas.

\begin{abstract}
This paper discusses the development of Cognitive Abilities of students to carry out inquiry activities, relating them to aspects involving neuroscience. The goal is to discuss and to analyze how investigative activities benefit the development of Cognitive Abilities for scientific research and activate Executive Functions in the light of studies of Neuropsychology, as the investigative activities stimulate students' thinking. To reach the goals proposed in this research we carried out a previous study and a later reflection on the theory of inquiry Cognitive Ability for scientific education and executive functions. Afterwards, it was possible to establish connections between the cognitive skills specified in this study and executive functions. As a result, we consider that the methodology of investigative activities in the teaching of Science improves cognitive skills for scientific investigation, as well as Executive Functions of Planning, Purposeful Action and Monitoring.
\end{abstract}

Keywords: Teaching science. Investigative activities. Executive functions.

\footnotetext{
${ }^{1}$ Universidade Norte do Paraná (Unopar), Londrina, PR, Brasil. E-mail: <andzomp@yahoo.com.br>.

${ }^{2}$ Instituto Federal do Paraná, Londrina, PR, Brasil.

${ }^{3}$ Universidade Estadual de Londrina (UEL), Londrina, PR, Brasil.
} 


\section{Introdução}

Vivemos numa sociedade que atribui grande valor ao desenvolvimento científico e tecnológico. Desse modo, as exigências atuais têm direcionado a educação dos estudantes de maneira que compreendam os conteúdos com visão holística, não estanque como no modelo cartesiano, e que possam, a partir do ensino que recebem na educação formal, conseguir resolver problemas em situações reais. Assim, ensinar a refletir, raciocinar e utilizar estratégias de resolução de problemas é uma necessidade fundamental da educação e relevante tarefa da escola. (FONSECA, 2008).

Neste sentido, a disciplina de Ciências Naturais tem por objetivos, além da aprendizagem de conceitos e conhecimentos, também o desenvolvimento nos educandos de habilidades que são inerentes a essa área de conhecimento. Pode-se considerar como habilidades cognitivas para investigação científica a capacidade de observar, registrar, analisar dados, comparar, perceber evidências, fazer inferências, concluir, aprimorar o raciocínio e argumentar.

Algumas dessas habilidades foram avaliadas a partir do desempenho dos alunos que participaram em 2015 da prova do Programme for International Student Assessment (PISA) - Programa Internacional de Avaliação de Estudantes -, desenvolvido e coordenado pela Organização para Cooperação e Desenvolvimento Econômico (OCDE) e pelo Instituto Nacional de Estudos e Pesquisas Educacionais Anísio Teixeira (Inep) no Brasil.

Analisamos os objetivos que constam nas questões da prova, em que estão descritos os processos cognitivos envolvidos em sua resolução que os alunos deveriam demonstrar ao resolverem algumas das perguntas, como identificar questões e evidências, elaborar, avaliar e comunicar conclusões. Esses processos cognitivos também constam como competências e habilidades na matriz de avaliação de Ciências do PISA 2012 (PISA..., 2013).

O exame do PISA realizado em 2015 avaliou estudantes de 76 países em provas de Leitura, Matemática e Ciências, sendo, no Brasil, aplicada ao primeiro ano do Ensino Médio. Nesse período de escolaridade, a área de Ciências Naturais compreende as disciplinas de Física, Biologia e Química. No ranking, o Brasil ficou classificado em $60^{\circ}$ lugar conforme divulgado em jornais em todo o Brasil e no site G1. (BRASIL..., 2015).

Neste estudo, não temos a pretensão de discutir o desempenho dos alunos brasileiros no PISA, mas de relacionar algumas das habilidades avaliadas e citadas na prova de Ciências com as Funções Executivas. As referidas habilidades são ainda necessárias ao estudante para favorecer o processo de Alfabetização Científica, conforme apontam Sasseron e Carvalho (2011).

Admitimos que em muitas de nossas escolas ainda há ênfase em um ensino livresco, sem a preocupação de que os estudantes desenvolvam habilidades cognitivas que podem ser proporcionadas pela aprendizagem das Ciências Naturais e, assim, possam também conhecer os aspectos que se relacionam à natureza do conhecimento científico. Em função dos resultados apresentados urge a necessidade de orientar professores de Ciências Naturais para possíveis soluções didáticas.

Diversos estudos têm sido desenvolvidos pela Didática das Ciências que apontam metodologias para promoverem atividades intelectuais dos alunos em oposição ao ensino meramente expositivo, em que há atuação intelectual mais passiva dos estudantes. Em se tratando de estratégias de ensino e aprendizagem, entre as diversas pesquisas que têm surgido nas últimas décadas, destaca-se uma linha que propõe a utilização de atividades investigativas no ensino, 
Atividades de investigação na disciplina de Ciências e desenvolvimento ...

como se pode observar em Azevedo (2006), Borges (2002), Carvalho (2006), Gil Pérez e Valdés Castro (1996), Sá (2009) e Zômpero e Laburú (2011). Esses pesquisadores defendem o uso de atividades investigativas no ensino, por promover o raciocínio e as habilidades cognitivas dos alunos, como as que foram anteriormente citadas.

Aliados aos estudos da Didática das Ciências, as Neurociências, entre elas aqui mais especificamente a Neuropsicologia, têm dado significativas contribuições a essa área de conhecimento, visto que desvelam os segredos do funcionamento mental humano, comprovando suas bases materiais. Um de seus objetos de estudo, as Funções Executivas, é foco central do presente trabalho, uma vez que se trata de um conjunto de ações mentais importantes para autorregulação da aprendizagem científica.

Buscamos responder por este estudo como o ensino de Ciências Naturais, baseado na perspectiva de inquiry, o ensino por investigação, estimula o uso de Funções Executivas de nossos estudantes. Portanto, nosso objetivo é discutir e analisar como as atividades investigativas desenvolvem Habilidades Cognitivas e ativam Funções Executivas, por meio de uma revisão e discussão da literatura referente aos estudos da Neuropsicologia, visto que as atividades investigativas cumprem o papel de estimular o raciocínio dos estudantes. Esta pesquisa é parte de um estudo mais amplo. Portanto, neste trabalho, para apresentar a correlação entre atividades investigativas, Habilidades Cognitivas e Funções Executivas, tomamos por base apenas as habilidades que foram avaliadas na prova do PISA de 2015: a resolução de problemas, percepção de evidências e capacidade de elaboração de conclusões e divulgação de resultados pelos estudantes.

\section{Neurociências, neuropsicologia e aprendizagem científica}

De acordo com a Sociedade Brasileira de Neurociências e Comportamento (SBNeC), Neurociência é um termo que traz em seu conceito a ideia de interdisciplinaridade, uma vez que engloba áreas de produção científica que realizam "estudo da estrutura e de todas as funções, normais e patológicas, do sistema nervoso" (TIMO-IARIA, 20--?), compreendendo atualmente o comportamento como forma de manifestação destas funções, estando indissociado do organismo.

Ainda segundo o autor, no Brasil múltiplos campos da Neurobiologia são explorados, como estudos de fisiologia e hodologia do sistema visual, memória e aprendizado, comportamentos defensivos, fisiologia do sono, fisiologia da atividade mental, regulação do sistema cardiovascular, regulação do sistema endócrino, comportamento alimentar e de ingestão de água e neurofarmacologia (TIMO-IARIA, 20--?). A Neuropsicologia é uma neurociência que trata desta relação entre comportamentos e fatores neurobiológicos, tendo como um de seus objetos de estudo, as Funções Executivas enquanto ações cognitivas especificamente humanas voltadas para autocontrole do comportamento. Outro objeto de estudo, a Aprendizagem é aqui vista como um complexo fenômeno neuropsicológico, e seu efeito, o Aprendizado enquanto mudança de comportamentos é resultado de modificações funcionais ou estruturais no Sistema Nervoso Central (SNC), de caráter mais ou menos permanente, que ocorrem em decorrência de estímulos ou experiências vividas pelo organismo. (ROTTA; OHLWAEILER; RIESGO, 2007).

Estímulos (dados, informações) que nos modificam neurologicamente são processados em diferentes níveis e nos chegam primeiramente a partir de terminações nervosas, organizadas 
funcionalmente em cinco sentidos. Voluntaria e involuntariamente, coletamos dados do meio ambiente externo e do nosso próprio organismo (informações proprioceptivas, enteroceptivas e memórias), com o objetivo de nos modificarmos e adaptarmos às diversas situações, obtermos benefícios, afastarmos ameaças e resolvermos problemas. $\mathrm{Na}$ verdade, de acordo com os princípios da ciência neural atual, organismo, cérebro, mente e ambiente integram-se numa extensão contínua, visto que "todos os processos mentais são biológicos e, portanto, qualquer alteração nesses processos é necessariamente orgânica”. (KANDEL; SCHWARTZ; JESSEL, 2003, p. 1275).

Pensando de modo neutro, ambientes educacionais, virtuais ou reais, como quaisquer outros, são fontes de estímulos que podem provocar alterações neurológicas e/ou neuropsicológicas, ou seja, aprendizado, independentemente da qualidade deste aprendizado, se relativo ou não ao conteúdo ensinado pelo professor ou material de ensino. No entanto, a intencionalidade pedagógica visa aprendizagem destes conteúdos, com o propósito maior do aprendiz se preparar para exercer controle motor, afetivo e cognitivo em situações presentes ou futuras que exijam sua adaptação, autodefesa, resolução de problemas ou que lhe possibilitem benefícios nos diversos ambientes naturais e culturais onde vive e viverá. Trata-se, portanto, de estimular Funções Executivas, enquanto formas superiores de uso de informações e expressão de conhecimentos ou performances, adotando procedimentos cognitivos de execução, regulação e controle de condutas (FONSECA, 2008), os quais dependem centralmente de atividades do Córtex Pré-Frontal, do adequado desenvolvimento e funcionamento de seus segmentos e núcleos (CORSO et al., 2013; ROTTA; OHLWAEILER; RIESGO, 2007).

Ardila (2008) afirma que o desenvolvimento de Funções Executivas depende, sobretudo, dos estímulos culturais (escolares, inclusive), por serem estas funções resultado da evolução de instrumentos linguísticos, o que envolve semântica, expressão oral e escrita. Fonseca (2008, p. 57), alinhado com tal afirmação, recorre a Vygotsky e Luria para concluir que o cérebro como "órgão da civilização" e "órgão da aprendizagem” transforma já muito cedo ação em pensamento, pela internalização da linguagem, e depois pensamento em ação, pela condução simbólica dos comportamentos. Tais processos cognitivos, propriamente humanos, são, enquanto conjunto, a principal função do Lobo Frontal na produção de condutas superiores.

Nesta mesma linha de raciocínio quanto à função da Educação de desenvolvimento de Habilidades Cognitivas, estão os métodos de Ensino de Ciências direcionados à atividade investigativa, a qual pode apresentar diferentes denominações conforme a literatura como, Ensino por Investigação, Ensino por Projetos e Inquiry, entre outros (ZÔMPERO; LABURÚ, 2011). Por meio de atividades investigativas, os alunos são conduzidos a fazer observações, criar perguntas, examinar livros e outras fontes de informação para saber o que já é conhecido, revisar o que já é conhecido sob a luz de experiências científicas, usar instrumentos para coletar, analisar e interpretar dados, propor respostas, explicações e previsões e comunicar os resultados. Isto requer identificação de hipóteses, uso de raciocínio crítico e lógico, bem como consideração de explicações alternativas. (OLSON; LOUCKS-HORSLEY, 2000).

Recentes estudos de Ergül et al. (2011) avaliaram se houve melhoras estatisticamente relevantes em habilidades e atitudes de investigação científica de alunos do ensino fundamental na Turquia, de acordo com seu nível escolar e idade, enquanto passavam por dois semestres de ensino baseado em atividade investigativa. Corroboraram outros estudos citados, reafirmando que quando alunos participam ativamente de investigações científicas, aprimoram habilidades como observação, comparação, classificação, inferência, predição, mensuração, evocação e inter- 
Atividades de investigação na disciplina de Ciências e desenvolvimento ...

pretação, formulação de modelos, construção de tabelas e gráficos, experimentação, operações, formulação de hipóteses, identificação e controle de variáveis.

\section{Funções executivas: diversos conceitos, modelos e componentes}

Corso et al. (2013) publicaram, recentemente, artigo de revisão em que discutem relações entre conceitos e modelos teóricos de Metacognição e de Funções Executivas, objetivando sua aplicação à área de Educação. As pesquisadoras apontam que um problema na busca de estabelecimento de relações entre esses conceitos é o fato da enorme abrangência de significações e modelos teóricos, tanto para o que se entende por Metacognição quanto para o que se entende por Funções Executivas, embora detectem evolução em sua diferenciação. De modo perspicaz, afirmam que isto acarreta dificuldades na área de pesquisa, justamente na operacionalização dos conceitos (CORSO et al., 2013), como vivenciamos no presente texto em que buscamos relacionar Habilidades Cognitivas utilizadas em atividades investigativas com Funções Executivas, sendo estas conceituadas e seus subcomponentes listados de diferentes formas. Em tempo, vale apontar que, como nossa pretensão é considerar uma possível forma de aproximação entre Educação (atividade investigativa no Ensino de Ciências, Habilidades Cognitivas) e Neuropsicologia (Funções Executivas), não nos deteremos sobre os conceitos de Metacognição (Psicologia Cognitiva).

Santos (2004) afirma que apesar da variação conceitual citada, determinadas características gerais das Funções Executivas são universais, ou seja, comuns. Estão relacionadas com controle voluntário e consciente sobre o ambiente e as ações necessárias para lidar com estímulos e respostas, de modo a alcançar um determinado objetivo; integram sensação, cognição e ação. Não se trata de uma unidade, visto seus diferentes processos de controle; aplicam-se às dimensões cognitivas, emocionais e sociais do comportamento humano.

Para Cypel (2007), Funções Executivas seriam funções responsáveis por iniciar, desenvolver uma atividade e atingir um objetivo determinado, gerenciando recursos cognitivo-comportamentais para planejar e regular o comportamento. As Funções Executivas organizariam atividades cognitivas relacionadas a percepções, memórias e praxias dentro de um contexto, visando eleger uma meta, decidir sobre o início ou não da proposta, planejar as etapas de realização, monitorar as etapas, comparando-as com um modelo proposto, modificar o modelo quando necessário, dar sequência ou interromper a proposta inicial, avaliar o resultado final em relação ao primeiro objetivo.

Segundo Uehara, Charchat-Fichman e Landeira-Fernandez (2013), Alexander Luria (1973 apud UEHARA, CHARCHAT-FICHMAN; LANDEIRA-FERNANDEZ, 2013, p. 29) foi o primeiro a utilizar a expressão Funções Executivas em artigo de 1968 e as entendia como última etapa do processamento de informações. A terceira unidade funcional de Luria, anatomicamente localizada predominantemente no Lobo Frontal, teria como funções programar, regular e verificar ações mentais, funções essas posteriormente identificadas como Funções Executivas.

Muriel Deutsch Lezak na década de 1980, pioneira na sistematização do conceito de Função Executiva (UEHARA, CHARCHAT-FICHMAN; LANDEIRA-FERNANDEZ, 2013), afirmava que estas seriam quatro: a formação de objetivos ou volição (vontade determina o objetivo), o planejamento (sequência de passos para se atingir uma meta), a realização do pla- 
no direcionado ao objetivo ou ação intencional (iniciar as ações, manter sequência, modificar ou interromper em caso de necessidade) e o desempenho eficaz ou efetivo (autocorreção, automonitoramento e autorregulação do comportamento) (CORSO et al., 2013; UEHARA, CHARCHAT-FICHMAN; LANDEIRA-FERNANDEZ, 2013).

Já Powell e Voeller (2004) dividem as Funções Executivas em dimensões referentes ao controle cognitivo (memória de trabalho, controle da atenção, planejamento, monitoramento, raciocínio abstrato e solução de problemas), ao controle comportamental (iniciativa de movimentos ou comportamentos, controle de impulso, antecipação de consequências, entre outras funções) e ao controle emocional (modulação da excitação emocional, modulação de humor, estratégias autotranquilizadoras).

Ylikoski e Hänninen (2003) organizam as Funções Executivas em quatro classes com seus subcomponentes: desejo ou vontade (antecipação, motivação, comportamento intencional), planejamento (conceitualização, tomada de decisão, desenvolvimento de esquema para executar plano), ação propositiva (programação da atividade, manutenção, integração e alternância de sequências de comportamentos, flexibilidade mental, inibição, controle da atenção e memória) e monitoramento (controle do desempenho efetivo, regulação de aspectos qualitativos do comportamento, utilização de feedback) (CORSO et al., 2013; YLIKOSKI; HÄNNINEN, 2003).

\section{Atividades investigativas, habilidades cognitivas para investigação científica e ensino de ciências}

A matriz de avaliação de Ciências do PISA 2012, cujo exame é aplicado a alunos da Educação Básica, aponta algumas competências e habilidades que necessitam ser desenvolvidas nas disciplinas que envolvem as Ciências da Natureza. A prova de Ciências do PISA objetiva avaliar se os alunos demonstram competências e habilidades para identificar questões científicas, isto é, reconhecer questões passíveis de investigação científica, elementos que devem ser comparados, variáveis a serem alteradas ou controladas, informações adicionais necessárias e ações para coletar dados relevantes; explicar fenômenos cientificamente, ou seja, descrever, interpretar fenômenos, prever mudanças e identificar descrições, explicações e previsões que sejam apropriadas cientificamente; utilizar evidências científicas, isto é, acessar informações, produzir argumentos e conclusões, procurar argumentos contrários e favoráveis às conclusões, identificar pressupostos, evidências e lógica nas conclusões, refletir sobre implicações sociais da ciência e da tecnologia; elaborar conclusões a partir das evidências e comunicar os resultados obtidos durante a realização da atividade. (INSTITUTO NACIONAL DE ESTUDOS E PESQUISAS EDUCACIONAIS ANÍSIO TEIXEIRA, 2013).

A proposta de utilização de atividades investigativas no ensino, também ditas inquiry, promove o desenvolvimento de diversas Habilidades Cognitivas para investigação científica, cujo conceito precisamos esclarecer. De acordo com Olson e Loucks-Horsley (2000), tais habilidades são aquelas que requerem dos estudantes saber aplicar ações de processamento de informações como observação, inferência e experimentação à produção de conhecimento científico, para o qual usam raciocínio e pensamento crítico, desenvolvendo sua compreensão a respeito de ciência. As atividades investigativas atendem, portanto, às necessidades educacionais contemporâneas apontadas por organizações internacionais e instituições governamentais. 
Pesquisas apontam que as atividades investigativas podem ser desenvolvidas com base em diferentes abordagens. Em estudos realizados por Zômpero e Laburú (2011) relativo aos aspectos históricos e às diferentes abordagens para a realização de atividades investigativas, os autores apontam que há consenso na literatura de que essas atividades devem sempre partir de um problema para ser analisado, para o qual os alunos devem emitir hipóteses, realizar um planejamento das atividades, interpretar as informações e comunicar os resultados.

Foram divulgadas no documento americano intitulado "Inquiry and the national science education standards: a guide for teaching and learning" (OLSON; LOUCKS-HORSLEY, 2000) as principais características que devem apresentar as atividades de inquiry de um modo geral. São elas o engajamento do estudante na atividade, priorização de evidências, formulação de explicações para as evidências, articulação das evidências ao conhecimento científico e comunicação dos resultados obtidos.

Carvalho (2006) afirma que para favorecer a construção de conhecimento, os professores devem propor aos alunos questões interessantes e desafiadoras para resolverem os questionamentos propostos, no intuito de promover a enculturação científica. A autora classifica a atuação do professor e dos alunos em diferentes níveis de envolvimento com a atividade investigativa e propõe uma graduação para estudar o que chama de graus de liberdade concedido pelos professores aos estudantes. Conforme a proposta da autora, admitimos ser mais apropriado às atividades desenvolvidas em sala de aula o que ela denomina como grau II de liberdade. Nesse nível, o professor propõe o problema, a elaboração de hipóteses e o plano de trabalho. Esses são realizados pelos alunos, mas com a orientação do professor. O registro dos dados é também realizado pelos estudantes com a orientação do professor e a conclusão pode ser elaborada pelo grupo de alunos, mas apresentada e discutida por toda a sala, ressaltando a necessidade de o conhecimento ser divulgado, assim como ocorre na ciência.

Apesar da polissemia associada ao termo "atividades de investigação", e da falta de consenso quanto às características das referidas atividades, admitimos que algumas delas devem estar presentes nas atividades investigativas como: a necessidade de um problema a ser investigado; o engajamento dos alunos para realizar as atividades; o levantamento de hipóteses, nas quais é possível identificar os conhecimentos prévios dos estudantes; a busca por informações, tanto dos experimentos, como pela bibliografia que possa ser consultada pelos alunos para ajudá-los na resolução do problema proposto na atividade; a elaboração da conclusão da atividade, momento em que há sistematização do conhecimento pelos estudantes e a comunicação dos estudos feitos pelos alunos para os demais colegas de sala, refletindo, assim, um momento de grande importância na comunicação do conhecimento, tal como ocorre na ciência.

Segundo Olson e Loucks-Horsley (2000), o ensino e a aprendizagem por atividade investigativa apresentam cinco propriedades específicas essenciais, ou seja, concernentes a todos os níveis escolares:

(1) Os aprendizes são motivados (engajados) por problemas científicos.

Esses problemas científicos são centrados em objetos, organismos e eventos do mundo natural. São problemas que por si mesmos conduzem à investigação, levam à coleta e uso de dados para desenvolver explicações para fenômenos científicos.

De acordo com Olson e Loucks-Horsley (2000), cientistas reconhecem dois tipos primários de questões científicas: as existenciais que procuram prova pela origem das coisas, aquelas que começam com "Por que (...)?"; e questões causais/funcionais, aquelas que iniciam 
com “Como (...)?”. Essas questões instigam outras indagações. As perguntas podem se originar do próprio aluno, do professor, dos materiais de ensino, da Internet ou de outros tipos de fontes. O professor tem o papel crítico de identificar questões, principalmente quando estas emergem dos próprios aprendizes. Atividades investigativas bem conduzidas evoluem a partir de questões que são significativas e relevantes para os estudantes, e também devem ser respondidas pelas observações e conhecimentos científicos dos estudantes, oriundos de fontes confiáveis.

(2) Os aprendizes priorizam evidências (provas), o que lhes permite desenvolverem e avaliarem explicações para problemas científicos.

A ciência se diferencia de outras formas de buscar explicações para os fenômenos naturais. Os cientistas se concentram em coletar dados a partir da observação de fenômenos. Suas evidências são obtidas por meio de observações e medidas em contextos naturais ou organizados, como os laboratórios. Usam seus sentidos, instrumentos para potencializá-los, como microscópios, ou para medir o que sentidos humanos não medem, como campos magnéticos. A precisão da evidência coletada é verificada checando-se medidas, repetindo observações, coletando novos tipos de dados relacionados ao mesmo fenômeno. A evidência está sujeita a questionamentos e investigações mais profundas. (OLSON; LOUCKS-HORSLEY, 2000).

O professor conduz a coleta de dados pelos estudantes levando-os a observar cuidadosamente seres e objetos na natureza; a realizar medidas (temperaturas, distâncias, tempo) registrando-as cuidadosamente; a observar reações e etapas de transformação dos fenômenos, registrando o progresso em gráficos; a coletar evidências a partir de informações dadas pelo professor, materiais de ensino e outras fontes. (OLSON; LOUCKS-HORSLEY, 2000).

(3) Os aprendizes formulam explicações a partir das evidências para responderem a problemas científicos.

Explicações científicas esclarecem causas para os efeitos e estabelecem relações baseadas em evidência e raciocínio lógico e, por isso, devem ser consistentes com evidências experimentais e observacionais sobre a natureza. Elas respeitam as regras para o que é evidência, estão abertas a críticas e requerem o uso de vários processos cognitivos geralmente associados com ciência. Por exemplo, classificação, análise, inferência e previsão, bem como processos gerais como raciocínio crítico e lógico. (OLSON; LOUCKS-HORSLEY, 2000). O professor exige e estimula, de modo crítico, explicações lógicas e bem fundamentadas por parte de seus alunos. Com respeito e zelo, ele os deixa conscientes de suas incoerências argumentativas, cria questionamentos intencionais para que os estudantes se atentem a informações ignoradas e relações precipitadas.

(4) Os aprendizes avaliam suas explicações próprias, oriundas da articulação das evidências, comparando com explicações alternativas, particularmente aquelas que refletem compreensões científicas já existentes.

Avaliação e possível eliminação ou revisão de explicações são uma característica que distingue investigações científicas de outras formas de investigação e suas consequentes explicações. Cientistas suportam questionamentos como, por exemplo, as provas oferecem suporte para a explicação proposta? A explicação responde adequadamente ao problema de pesquisa? Há alguma falha no raciocínio que relaciona as evidências à explicação? Outras explicações racionais podem ser elaboradas a partir das evidências? (OLSON; LOUCKS-HORSLEY, 2000).

Assim, de modo adequado ao seu nível de desenvolvimento, é preciso possibilitar que os alunos façam relações entre os resultados que eles encontram e o conhecimento científico prévio, modificando, atualizando dados, revisando ou confirmando suas ideias. 
Atividades de investigação na disciplina de Ciências e desenvolvimento ...

(5) Os aprendizes comunicam e justificam suas propostas de explicação.

Cientistas comunicam suas explicações de modo que seus resultados possam ser reproduzidos. Isso requer clara articulação entre problema de pesquisa, evidências, explicação proposta e revisão de explicações alternativas, o que possibilita revisões mais profundas, oportunidades para outros cientistas usarem a explicação para trabalharem sobre novos problemas. (OLSON; LOUCKS-HORSLEY, 2000).

Levar os alunos a compartilhar suas explicações possibilita que outros estudantes façam perguntas, examinem as evidências, identifiquem raciocínios falhos, apontem fatos que estão além das evidências e sugiram explicações alternativas para as mesmas observações. Como resultado, os alunos podem resolver contradições e consolidar argumentos baseados em experiências. (OLSON; LOUCKS-HORSLEY, 2000).

Seria possível então que, ao conduzir a participação dos alunos em atividades investigativas de acordo com a metodologia esclarecida acima, estaríamos não apenas estimulando o desenvolvimento de Habilidades Cognitivas para investigação científica, mas também o aprimoramento no uso das Funções Executivas de nossos alunos? Ou seja, seria possível estabelecermos relações entre Habilidades Cognitivas necessárias à investigação científica e Funções Executivas?

\section{Possíveis relações entre funções executivas e habilidades cognitivas necessárias em atividades investigativas}

Conforme exposto até aqui, temos ao alcance diferentes modelos teóricos acerca de Funções Executivas. Temos também seis classificações de Habilidades Cognitivas para atividades investigativas de acordo com os parâmetros do National Research Council (NRC) (OLSON; LOUCKS-HORSLEY, 2000). São elas: elaborar e identificar problemas, planejar e conduzir investigações, coletar dados para resolver o problema, associar evidências para elaborar explicações, reconhecer e analisar explicações alternativas, comunicar procedimentos e resultados de investigação.

Devido às limitações próprias deste texto, optamos por destacar das seis Habilidades Cognitivas para atividades investigativas que apresentamos, apenas três, coletar dados para resolver o problema, associar evidências para elaborar explicações e comunicar procedimentos e resultados de investigações, pois estão associadas mais diretamente às habilidades que foram exigidas dos estudantes no referido exame PISA: identificar questões e evidências, elaborar, avaliar e comunicar conclusões. Entendemos, assim, que as atividades investigativas objetivam desenvolver Habilidades Cognitivas que capacitariam os estudantes a atingirem objetivos propostos para o processo de entendimento da natureza da ciência, sendo esse um aspecto necessário à alfabetização científica. (SASSERON; CARVALHO, 2011).

Conforme explicamos acima, intencionamos ainda relacionar Habilidades Cognitivas para investigação científica com Funções Executivas que estariam implícitas em sua demonstração. Tais relações são possíveis devido à amplitude das Funções Executivas, uma vez que estas são universalmente aplicadas em diversas situações, como as que exigem planejamento, ações dirigidas e monitoramento de ações. Para isso, faz-se necessária outra simplificação, ou seja, precisamos adotar um dentre os diversos modelos teóricos sobre Funções Executivas existentes. 
Devido à riqueza de subcomponentes explícitos mais específicos dentro de quatro classes de Funções Executivas, optamos pelo modelo de Ylikoski e Hänninen (2003), de modo que o leitor possa imaginar de forma mais nítida aquilo que poderia estar mais ou menos implícito em outros modelos semelhantes, como os apresentados por Corso et al. (2013), Cypel (2007), Santos (2004) e Uehara, Charchat-Fichman e Landeira-Fernandez (2013), sem desmerecê-los obviamente. Assim, ainda visando clareza expositiva, organizamos a seguir nossa proposta de relação entre as três Habilidades Cognitivas para atividades investigativas segundo o NRC, também exigidas pelo exame do PISA 2012, e Funções Executivas segundo o modelo de Ylikoski e Hänninen (2003), necessárias à sua demonstração.

No que concerne à classe de Funções Executivas "Desejo ou Vontade" de Ylikoski e Hänninen (2003) e seus subcomponentes (antecipação, motivação, comportamento intencional), entendemos que toda ação voluntária dirigida para se atingir algum propósito tem como base a vontade de atingir esta finalidade (engajamento), o que envolve antecipar o que necessita ser feito, ter um motivo para fazê-lo e agir intencionalmente. Assim, durante a atividade investigativa, para usar instrumentos para coletar informações, associar evidências para elaborar explicações ou comunicar procedimentos e resultados de investigações, o estudante pesquisador precisa agir intencionalmente para atingir tais propósitos, ainda que seus objetivos pessoais não coincidam com os do professor.

Quanto às demais três classes de Funções Executivas de Ylikoski e Hänninen (2003), trataremos da correspondência com Habilidades Cognitivas de modo mais detalhado. Antes, porém, para que o leitor tenha clareza das relações que estabelecemos, propomos a seguir uma tabela das relações entre Habilidades Cognitivas, Classes de Funções Executivas e Funções Executivas (Quadro 1), descrevendo sumariamente as Funções Executivas. A descrição sumária das Funções Executivas revela a aplicabilidade universal destas funções às três Habilidades Cognitivas, o que fica mais esclarecido no texto que segue ao quadro.

A seguir, detalhamos como percebemos as aplicações de Funções Executivas às Habilidades Cognitivas necessárias em atividades de investigação científica. As implicações didáticas destas relações remetem à função que professores de Ciências Naturais têm de estimular, orientar e avaliar seus estudantes quanto aos comportamentos descritos em cada função executiva aplicada ao longo das práticas de investigação científica nas escolas. 
Atividades de investigação na disciplina de Ciências e desenvolvimento ...

Quadro 1. Relações entre Habilidades Cognitivas (NRC) e Classes de Funções Executivas e Funções Executivas

\begin{tabular}{|c|c|c|}
\hline $\begin{array}{l}\text { Habilidades } \\
\text { cognitivas } \\
\text { (NRC) }\end{array}$ & $\begin{array}{l}\text { Classes de } \\
\text { funções } \\
\text { executivas }\end{array}$ & Funções executivas \\
\hline \multirow{5}{*}{$\begin{array}{l}\text { I. Coletar } \\
\text { dados para } \\
\text { resolver o } \\
\text { problema }\end{array}$} & \multirow{3}{*}{ Planejamento } & Conceitualização - atribuir significado \\
\hline & & Tomada de decisão - determinar ações \\
\hline & & $\begin{array}{l}\text { Desenvolvimento de esquema para executar plano - sequenciar } \\
\text { ações }\end{array}$ \\
\hline & \multirow{6}{*}{ Ação Propositiva } & Programação da atividade - organizar etapas \\
\hline & & $\begin{array}{l}\text { Manutenção, Integração e Alternância de sequências de } \\
\text { comportamentos - manter, cuidar de coesão e coerência, e } \\
\text { mudar comportamentos. }\end{array}$ \\
\hline \multirow{4}{*}{$\begin{array}{l}\text { II. Associar } \\
\text { evidências } \\
\text { para elaborar } \\
\text { explicações }\end{array}$} & & Flexibilidade mental - alterar esquemas prévios. \\
\hline & & Inibição - controlar ações precipitadas. \\
\hline & & $\begin{array}{l}\text { Controle da atenção - utilizar modos de atenção sustentada, } \\
\text { alternada, seletiva e dividida. }\end{array}$ \\
\hline & & $\begin{array}{l}\text { Memória - utilizar memórias de trabalho, de curto prazo e de } \\
\text { longo prazo. }\end{array}$ \\
\hline \multirow{3}{*}{$\begin{array}{l}\text { III. Comunicar } \\
\text { procedimentos } \\
\text { e resultados de } \\
\text { investigações }\end{array}$} & \multirow{3}{*}{ Monitoramento } & $\begin{array}{l}\text { Controle do desempenho efetivo - manter ações de acordo com } \\
\text { parâmetros. }\end{array}$ \\
\hline & & $\begin{array}{l}\text { Regulação de aspectos qualitativos do comportamento - regular } \\
\text { modos de agir. }\end{array}$ \\
\hline & & $\begin{array}{l}\text { Utilização de feedback - rever e alterar ações a partir de } \\
\text { resultados }\end{array}$ \\
\hline
\end{tabular}

Fonte: adaptado de Olson e Loucks-Horsley (2000) e de Ylikoski e Hänninen (2003).

\section{Habilidade cognitiva: coletar dados para resolver o problema}

I - Classe de Funções Executivas: Planejamento

Funções Executivas:

- Conceitualização: cada informação coletada pelo estudante pesquisador precisa ser identificada e compreendida, o que implica na internalização de seu significado;

- Tomada de decisão: ao coletar dados, o processo decisório é contínuo sobre o que, quanto, como e quando coletar;

- Desenvolvimento de esquema para executar plano: a coleta científica obedece a uma sequência padronizada e sistemática de ações e técnicas por parte do estudante pesquisador.

II - Classe de Funções Executivas: Ação Propositiva

Funções Executivas

- Programação da atividade: a coleta de informações deve obedecer a etapas previamente estabelecidas para se alcançar objetivos;

- Manutenção, Integração e Alternância de sequências de comportamentos: ao longo da coleta, a organização do estudante pesquisador deve ser constante quanto aos elementos 
coletados, registros de tempo, espaço e medidas; fatores que dificultam a coleta devem ser superados; informações precisam ser coletadas mais de uma vez. As ações de relacionar, agrupar e classificar informações precisam estar integradas para que dados não se percam ou deixem de ser considerados. Condições não previstas podem determinar alteração da sequência e dos tipos de comportamento planejados para a coleta de informações;

- Flexibilidade mental: é importante para o estudante que, ao desenvolver uma investigação, esteja aberto à possibilidade de abandonar ou modificar suposições e ações planejadas em decorrência de mudanças das condições. Informações antes consideradas relevantes à coleta podem deixar de ser e outras consideradas irrelevantes podem vir a ser relevantes;

- Inibição: a inibição de comportamentos impulsivos e precipitados é necessária para que se tenha cuidado na quantidade e na qualidade da coleta realizada.

- Controle da atenção: processos como atenção sustentada, alternada, seletiva e dividida são continuamente utilizados durante processos de coleta, visto o risco de se ignorar ou perder informações por distrações;

- Memória: processos de memória de trabalho, de curto prazo e de longo prazo estão em contínua ação para uma coleta eficiente, o que significa ter em mente o que já se coletou e as relações entre os elementos coletados, seus significados novos e aqueles significados de elementos registrados na memória de longo prazo.

III - Classe de Funções Executivas: Monitoramento

Funções Executivas:

- Controle do desempenho efetivo: ao fim da coleta, dados precisam ter sido coletados de maneira completa e precisa para se atingir o objetivo desta etapa de investigação científica, o que exige do estudante autocontrole consciente baseado em parâmetros de busca e alcance das metas, geralmente fornecidos pelo professor;

- Regulação de aspectos qualitativos do comportamento: o rigor metodológico exigido pela etapa de coleta de dados exige de quem realiza atividade investigativa o mesmo rigor no cuidado com a qualidade de suas ações, uso de instrumentos e organização dos dados;

- Utilização de feedback: conferir continuamente se cada etapa da coleta de dados foi bem feita de acordo com o planejado e com os parâmetros é fundamental para que todas as etapas da coleta levem ao fim bem sucedido.

\section{Habilidade cognitiva: associar evidências para elaborar explicações}

I - Classe de Funções Executivas: Planejamento

Funções Executivas:

- Conceitualização: soluções para problemas científicos e explicações exigem relações logicamente ordenadas entre problemas, evidências e hipóteses, portanto, o significado de cada elemento associado precisa estar claro para que a associação seja bem feita. O professor de Ciências tem aqui mais uma função de destaque, uma vez que os conceitos precisam antes ser formados;

- Tomada de decisão: associações entre evidências podem ser precipitadas ou razoáveis, exigindo autocrítica e tomadas de decisão maduras por parte do estudante pesquisador, para serem estabelecidas ou não; 
. Desenvolvimento de esquema para executar plano: a construção de argumentos explicativos exige ações para associar adequadamente evidências, as quais precisam ser previamente organizadas e sequenciadas em esquemas de ação mental.

II - Classe de Funções Executivas: Ação Propositiva

Funções Executivas:

- Programação da atividade: associar evidências implica em categorização dos dados, detecção de aspectos substanciais comuns a serem associados. Ordem e minúcia estão implícitas em atividades bem programadas. $O$ professor se assegura disso ao fornecer ou requisitar um plano ou projeto de investigação por parte do estudante;

- Manutenção, Integração e Alternância de sequências de comportamentos: durante a associação de evidências, o estudante pesquisador precisa manter percepção de quando elas são suficientes ou não, que evidências abandonar, que novas evidências precisam ser buscadas e associadas. Os atos em si de associar evidências e de construir um argumento são integrados, visto que o que antes estava disperso, oculto e não relacionado deixa então de ser. Pode ser nociva a perseveração em associar dados de acordo com uma etapa planejada, quando o contexto impõe que outras informações e suas associações precisem ser priorizadas. O professor de Ciências deve deixar claro que associações são flexíveis, de modo que o estudante alterne suas ações quando necessário;

- Flexibilidade mental: o objetivo maior de ter um argumento explicativo aceito por ser bem construído com base em evidências forte e logicamente associadas faz com que a flexibilidade mental seja imprescindível. A investigação científica, por natureza, exige contínua abertura a mudanças nos padrões de pensamento de quem a realiza, associando e desassociando informações, reformulando explicações;

- Inibição: um bom exemplo da necessidade da Função Executiva de inibição é a forte crença numa hipótese explicativa, carregada afetivamente, o que pode levar estudantes pesquisadores mais imaturos a forçar associações incoerentes entre evidências ou até mesmo a criar evidências que não existem de fato;

- Controle da atenção: falhas atencionais podem explicar como importantes evidências deixam de ser percebidas, logo, associadas; ou são associadas de modo parcial e indevido a outras na construção dos argumentos;

- Memória: muitas evidências são associadas durante a construção do argumento explicativo. É importante que o elaborador as tenha todas em mente, sobretudo pelo risco de uma associação entrar em conflito com outra feita anteriormente e para isso, a Memória de Trabalho é essencial. Associações e hipóteses realizadas antes pelo próprio estudante pesquisador e outros pesquisadores cujos trabalhos estudou precisam ser novamente associadas e criticadas durante a elaboração de dados, exigindo Memória de Trabalho tanto quanto Memórias de Longo Prazo semânticas e episódicas.

III - Classe de Funções Executivas: Monitoramento

Funções Executivas:

- Controle do desempenho efetivo: o investigador científico visa propor a melhor hipótese de solução possível para o problema pesquisado e para tal exerce intensa autocrítica com relação às suas próprias associações de evidência e argumentos explicativos, adotando o 
princípio da falseabilidade sobre si mesmo. O professor de Ciências muitas vezes precisa exercer esta função, justamente para favorecer o amadurecimento desta Função Executiva em seu aluno;

- Regulação de aspectos qualitativos do comportamento: o modo como as associações são realizadas deve passar por crivo qualitativo, uma vez que associações incorretas e superficiais podem se dar como consequência de pouca autoexigência qualitativa;

- Utilização de feedback: esta Função Executiva revela imenso valor para esta Habilidade Cognitiva, visto que a autocrítica e a reformulação constante dos argumentos explicativos para seu aprimoramento são nítidos usos do feedback.

\section{Habilidade cognitiva: comunicar procedimentos e resultados de investigações}

I - Classe de Funções Executivas: Planejamento

Funções Executivas:

- Conceitualização: antes de estar claro para o público-alvo da comunicação científica, os significados dos termos utilizados ao longo da comunicação precisam estar claros para o próprio estudante pesquisador. O professor de Ciências pode realizar ensaios prévios de comunicação, nos quais exige explicações conceituais de seus alunos a respeito de procedimentos utilizados e resultados da pesquisa;

- Tomada de decisão: comunicações precisam atingir seus objetivos ao mesmo tempo de modo rico e sintético, o que implica em processos decisórios sobre o que manter e o que ocultar;

- Desenvolvimento de esquema para executar plano: as ações explicativas a respeito da metodologia aplicada e a síntese das conclusões retiradas dos elementos observados e associados precisam ser previamente organizados e sequenciados em esquemas de ação mental e física, visto a necessidade de uma apresentação compreensível por todos.

II - Classe de Funções Executivas: Ação Propositiva

Funções Executivas:

- Programação da atividade: um discurso coerente revela metodologia e evidências relacionadas dentro de uma ordem, de modo que a explicação seja válida e convincente. Isso exige programação de ações por parte do estudante pesquisador auxiliado por seu professor;

- Manutenção, Integração e Alternância de sequências de comportamentos: durante a comunicação, escrita, oral ou de outra modalidade, dependendo do contexto, é possível que os procedimentos adotados necessitem ser mais ou menos detalhados, e os resultados novamente justificados com outras palavras ou diferentes modalidades de apresentação, o que exige manutenção ou alternância de ações. O estudante pesquisador precisa ter ações integradas ao demonstrar como os procedimentos adotados em sua metodologia de trabalho são coerentes com o problema e os objetivos que determinou;

- Flexibilidade mental: esta Função Executiva pode ser necessária devido ao processo de comunicação em si mesmo, pois a linguagem e as modalidades de apresentação pensadas pelo investigador podem não ser claras e compreensíveis do ponto de vista de quem é informado, exigindo readaptações semânticas e sintáticas, por exemplo;

- Inibição: motivados emocionalmente pela apresentação de seu trabalho, estudantes pesquisadores podem apresentar explicações excessivas, incompletas, conclusões inadequada- 
mente generalistas ou precipitadas. São formas de apresentação frágeis diante de contra-argumentação, resultado de dificuldade de inibição de impulsos;

- Controle da atenção: além da necessidade de coesão, sem pontos desassociados a esclarecer, o discurso explicativo precisa de início, meio e fim, o que implica em atenção sustentada, alternada, seletiva e dividida;

- Memória: toda comunicação implica necessariamente no uso de Memória de Curto Prazo, para manter em mente informações fornecidas e elaboradas enquanto se comunica as seguintes para garantir coesão; e de Memórias de Trabalho e de Longo Prazo, para coletar dados presentes no ambiente externo e associá-los com dados consolidados em forma de memórias aprendidas.

III - Classe de Funções Executivas: Monitoramento

Funções Executivas:

- Controle do desempenho efetivo: comunicações de procedimentos e resultados precisam ser claras e compreensíveis, justamente para que sejam passíveis de contra-argumentação e consequente evolução, de acordo com princípios da ciência e objetivos da comunicação científica. O controle destes e outros parâmetros qualitativos do discurso depende desta Função Executiva, claramente estimulada pelo trabalho do professor enquanto regulador do estudante;

- Regulação de aspectos qualitativos do comportamento: quando textos e outras modalidades de comunicação explicativa são mais aprofundados ou sintetizados, enfatizados ou suavizados, está presente o trabalho de regulação do comportamento comunicativo pelo próprio estudante pesquisador que comunica;

- Utilização de feedback: as respostas fornecidas por aqueles que são alvos da comunicação são usadas como fonte de dados para que o estudante pesquisador reformule ou confirme a qualidade de sua apresentação de procedimentos e resultados.

\section{Considerações finais}

O meio científico educacional é rico em pesquisas, artigos e bibliografias que apontam algumas constatações claras para o surgimento de uma nova filosofia pedagógica. Considerando a expressiva quantidade de saberes produzidos no meio científico, o pouco tempo para transmiti-lo e o fácil acesso individual à informação, sobretudo pelas redes de computadores, mostra-se imperioso ensinar a aprender ou aprender a aprender, estimulando operações mentais eficientes dos alunos para trabalharem de forma autônoma com as informações. A conclusão eficiente dessas operações deve resultar na percepção de princípios universais, aplicáveis em diversos contextos e situações. Consequentemente, para tal aplicação mostra-se fundamental, no meio escolar e acadêmico, a vivência, por parte dos aprendizes, da necessidade de conhecer e elaborar respostas científicas para os problemas. Dessa forma, torna-se prioritário que os alunos sejam preparados para refletirem, desenvolverem o senso crítico numa sociedade com grandes avanços tecnológicos e científicos.

A aplicação metodológica de atividades investigativas no ensino de Ciências pode atender a este propósito, uma vez que ao requisitar e aprimorar o exercício de Habilidades Cognitivas para investigação científica, necessariamente se ativaria o uso de Funções Executivas, 
como as que estão discriminadas nas classes de Desejo ou Vontade, Planejamento, Ação Propositiva e Monitoramento. O uso constante de tais habilidades e funções resultaria em mudanças estruturais/funcionais do SNC como todo aprendizado efetivo, de acordo com os princípios da neuroplasticidade, acarretando em mudanças de comportamento, visto a indissociabilidade entre desenvolvimento neurobiológico, ações físicas e mentais.

Tanto as Habilidades Cognitivas quanto às Funções Executivas mencionadas, uma vez desenvolvidas, se aplicariam a diversos outros contextos e situações, presentes e futuros, da vida do estudante. Formado de acordo com um autêntico Letramento Científico, o estudante estaria preparado e instrumentalizado cognitivamente para lidar e solucionar problemas nos ambientes material, intelectual e cultural de sua vida como um todo, para atuar e opinar com criticidade na sociedade atual.

\section{Agradecimento}

Os autores agradecem o auxílio financeiro da Fundação Nacional de Desenvolvimento do Ensino Superior Particular (FUNADESP).

\section{Referências}

ARDILA, A. On the evolutionary origins of executive functions. Brain and Cognition, Maryland Heights, v. 68, n. 1, p. 92-99, 2008.

AZEVEDO, M. C. P. S. Ensino por investigação: problematizando as atividades em sala de aula. In: CARVALHO, A. M. P. et al. (Org.). Ensino de ciências: unindo a pesquisa e a prática. São Paulo. Thomson, 2006.

BORGES, A. T. Novos rumos para o laboratório escolar de ciências. Caderno Brasileiro de Ensino de Física, Florianópolis, v. 19, n. 3, p. 291-313, 2002.

BRASIL ocupa $60^{\mathrm{a}}$ posição em ranking de educação em lista com 76 países. G1, São Paulo, 13 maio 2015. Disponível em: <http://g1.globo.com/educacao/noticia/2015/05/brasilocupa-60-posicao-em-ranking-de-educacao-em-lista-com-76-paises.html>. Acesso em: 13 de maio, 2015.

CARVALHO, A. M. P. Las práctices experimentales en el proceso de enculturación científica. In: QUINTANILLA GATICA, M.; ADÚRIZ-BRAVO, A. (Ed.). Enseñar ciencias en el nuevo milenio: retos e propuestas. Santiago: Universidade Católica de Chile, 2006.

CORSO, H. V. et al. Metacognição e funções executivas: relações entre os conceitos e implicações para a aprendizagem. Psicologia: teoria e pesquisa, Brasília, v. 29, n. 1, p. 21-29, 2013. Disponível em: <http://dx.doi.org/10.1590/S0102-37722013000100004>. Acesso em: 17 abr. 2017. 
Atividades de investigação na disciplina de Ciências e desenvolvimento ...

CYPEL, S. O papel das funções executivas nos transtornos da aprendizagem. In: ROTTA, N. T.; OHLWAEILER, L.; RIESGO, R. S. Transtornos de aprendizagem: abordagem neurobiológica e multidisciplinar. Porto Alegre: Artmed, 2007. p. 375-387.

ERGÜL, R. et al. The effects of inquiry-based science teaching on elementary school students' science process skills and science attitudes. Bulgarian Journal of Science and Education Policy, Sofia, v. 5, n. 1, p. 48-68, 2011.

FONSECA, V. Cognição, neuropsicologia e aprendizagem: abordagem neuropsicológica e psicopedagógica. Petrópolis: Vozes, 2008.

GIL PÉREZ, D.; VALDÉS CASTRO, P. La orientación de las prácticas de laboratorio como investigación: un ejemplo ilustrativo. Enseñanza de las Ciencias, Barcelona, v. 14, n. 2, p. 155-163, 1996. Disponível em: < http://www.raco.cat/index.php/Ensenanza/article/ view/21444/93407>. Acesso em: 17 abr. 2017.

INSTITUTO NACIONAL DE ESTUDOS E PESQUISAS EDUCACIONAIS ANÍSIO TEIXEIRA. Matriz de avaliação de ciências. [2013]. Disponível em: < http://download. inep.gov.br/acoes_internacionais/pisa/marcos_referenciais/2013/matriz_avaliacao_ciencias. pdf>. Acesso em: 17 abr. 2017.

KANDEL, E.; SCHWARTZ, J. H.; JESSEL, T. M. Princípios da neurociência. Barueri: Manole, 2003.

OLSON, S.; LOUCKS-HORSLEY, S. (Ed.). Inquiry and the national science education standards: a guide for teaching and learning. Washington: National Research Council, 2000.

PISA 2012 assessment and analytical framework: mathematics, reading, science, problem solving and financial literacy. Paris: OECD, 2013. Disponível em: <http://dx.doi. org/10.1787/9789264190511-en>. Acesso em: 17 abr. 2017.

POWELL, K. B.; VOELLER, K. K. Prefrontal executive function syndromes in children. Journal of Child Neurology, Thousand Oaks, v. 19, n. 10, p. 785-797, 2004.

ROTTA, N. T.; OHLWAEILER, L.; RIESGO, R. S. Transtornos de aprendizagem: abordagem neurobiológica e multidisciplinar. Porto Alegre: Artmed, 2007.

SÁ, E. F. Discursos de professores sobre ensino de ciências por investigação. 2009. 186 f. Tese (Doutorado em Educação) - Universidade Federal de Minas Gerais, Belo Horizonte, 2009.

SANTOS, F H. Funções executivas. In: ANDRADE, V. M.; SANTOS, F. H.; BUENO, O. F. (Ed.). Neuropsicologia hoje. São Paulo: Artes Médicas, 2004. p. 125-134.

SASSERON, L. H; CARVALHO, A.M. P. Alfabetização científica: uma revisão bibliográfica. Investigações em Ensino de Ciências, Porto Alegre, v. 16, n. 1, p. 59-77, 2011.

TIMO-IARIA, C. Neurofisiologia no Brasil: história. [20--?]. Disponível em: <http:// www.sbnec.org.br/site/texto.php?id_texto=3 >. Acesso em: 17 abr. 2017. 
UEHARA, E.; CHARCHAT-FICHMAN, H.; LANDEIRA-FERNANDEZ, J. L. Funções executivas: um retrato integrativo dos principais modelos e teorias desse conceito. Neuropsicologia Latinoamericana, Bogotá, v. 5, n. 3, p. 25-37, 2013. Disponível em: <http://neuropsicolatina.org/index.php/Neuropsicologia_Latinoamericana/article/ view/145/119>. Acesso em: 18 abr. 2017.

YLIKOSKI, R.; HÄNNINEN, T. Assessment of executive function in clinical trials. International Psychogeriatrics, Cambridge, v. 15, n. S1, p. 219-224, 2003. Disponível em: <https://doi.org/10.1017/S1041610203009232>. Acesso em: 18 abr. 2017.

ZÔMPERO, A. F.; LABURÚ C. E. Atividades investigativas no ensino de ciências: aspectos históricos e diferentes abordagens. Ensaio: pesquisa em educação em ciências, Belo Horizonte, v. 13, n. 3, p. 67-80, 2011. Disponível em: <http://www.scielo.br/pdf/epec/ v13n3/1983-2117-epec-13-03-00067.pdf>. Acesso em: 18 abr. 2017.

Artigo recebido em: 04/12/2015. Aceito em: 02/11/2016.

Endereço para contato: Universidade Norte do Paraná, Centro de Pesquisa, Jardim Piza, Rua Marselha 591, 86015-320, Londrina, PR, Brasil. 